
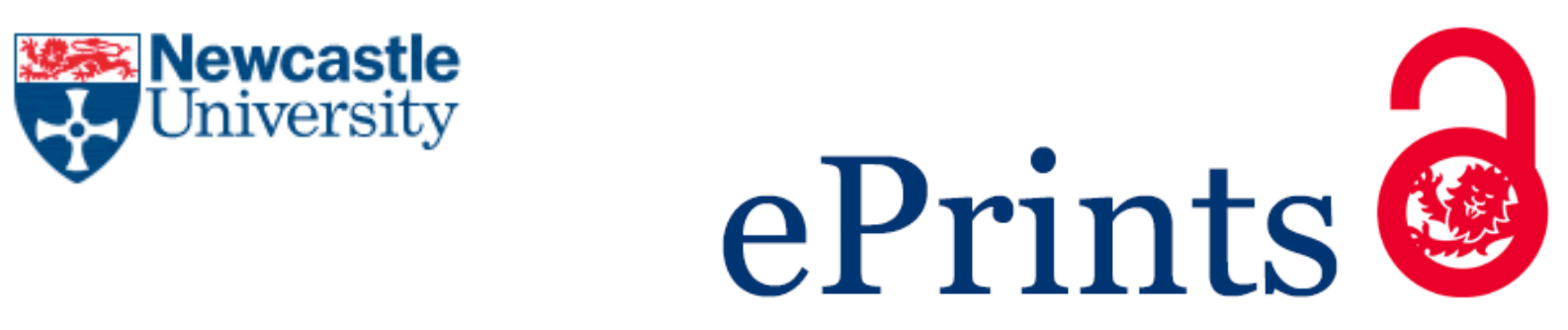

Baxter EM, Adeleye OO, Jack M, Farish M, Ison SH, Edwards SA.

Achieving optimum performance in a loose-housed farrowing system for sows: the effects of space and temperature. Applied Animal Behaviour Science 2015, 169, 9-16.

\title{
Copyright:
}

(C) 2015. This manuscript version is made available under the CC-BY-NC-ND 4.0 license

DOI link to article:

http://dx.doi.org/10.1016/j.applanim.2015.05.004

Date deposited:

$10 / 02 / 2016$

Embargo release date:

26 May 2016

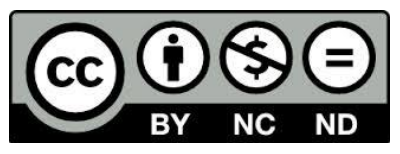

This work is licensed under a

Creative Commons Attribution-NonCommercial-NoDerivatives 4.0 International licence 


\section{Achieving optimum performance in a loose-housed farrowing system for sows: the effects of} space and temperature

Emma M. Baxter ${ }^{1 *}$, Oluwagbemiga O. Adeleye ${ }^{2}$, Mhairi C. Jack ${ }^{1}$, Marianne Farish ${ }^{1}$, Sarah H. Ison ${ }^{1}$ and Sandra A. Edwards ${ }^{2}$

${ }^{1}$ Animal Behaviour and Welfare, Animal and Veterinary Sciences Group, Scotland's Rural College, West Mains Road, Edinburgh, EH9 3JG, UK

${ }^{2}$ Newcastle University, School of Agriculture, Food and Rural Development, Agriculture Building, Newcastle upon Tyne NE1 7RU, UK

*Corresponding author: Emma M. Baxter: Emma.Baxter@sruc.ac.uk

\section{Abstract}

Piglet survival relies on interactive influences of the sow, her piglets and their environment. There are a number of design challenges in a loose-housed farrowing and lactation system to optimise this dynamic, including achieving farrowing in the desired location (i.e. a protected nest area) and minimising crushings. The PigSAFE (Piglet and Sow Alternative Farrowing Environment) pen was developed with these challenges in mind. It has different areas to fulfil different biological and managerial needs, including a solid-floored nest area with piglet protection features (sloped walls, heated creep) intended for farrowing. Two hypotheses regarding pen design features to optimise farrowing location and improve piglet survival were tested: (i) greater space would improve maternal behaviour; and (ii) a heated nest-site would be more attractive to the farrowing sow. PigSAFE was adapted to give a LARGE treatment, $9.7 \mathrm{~m}^{2}$ in total with a nest area of $4.0 \mathrm{~m} 2$, and a SMALL treatment, same design but $7.9 \mathrm{~m}^{2}$ in total with a nest area of $3.3 \mathrm{~m}^{2}$. The nest floor was heated to either $30^{\circ} \mathrm{C}$ (T30) or $20^{\circ} \mathrm{C}$ (T20) from $48 \mathrm{~h}$ before until $24 \mathrm{~h}$ after farrowing. A $2 \times 2$ factorial design saw 88 Large White $\times$ Landrace sows randomly assigned to space and temperature treatments. Generalised linear mixed models were used to analyse performance data. Farrowing location analysis involved dividing the pen into seven areas (L1-L7); L1 deemed the safest location for the piglets to be born (in the nest, furthest from dunging area, closest to creep) and L7 the least protected (in the dunging area). Of all the piglets born $97 \%$ were born in the nest area. The majority of sows started farrowing in L1 (56\%), with $39 \%$ of remaining piglets being born in this location. There was a significant Space $\times$ Temperature interaction for farrowing location $(P=0.011)$ with SMALL T20achieving the most L1 births. Temperature had no significant influence on piglet survival (Total mortality $\mathrm{P}=0.401$; Live-born mortality $\mathrm{P}=0.826$ ). However space influenced mortality, with significantly greater live-born mortality when sows were afforded a larger farrowing space (LARGE = 
$18.1 \%$ vs. $\mathrm{SMALL}=10.9 \% \mathrm{P}=0.028)$. There were no significant interactions between space and temperature for either total mortality $(P=0.394)$ or live-born mortality $(P=0.685)$. The overall design successfully promoted farrowing in the nest location, irrespective of nest size and floor temperature. The higher piglet mortality in the LARGE treatment suggests that the larger nest size was less protective for the piglets and thus a smaller nest, within an adequate total pen size for differentiation of functional areas, would be recommended.

Keywords: free farrowing, space, temperature, piglet survival, maternal behaviour

\section{Introduction}

Confinement of the sow during farrowing and lactation is a welfare issue which is a continuing focus for public concern and debate. At the present time, the majority of sows farrow in conventional farrowing crates (approximately $60 \%$ of sows farrow indoors in the UK with $96 \%$ of these in crates Guy et al., 2012; 95\% in EU and 83\% in USA - EFSA, 2007; NAHMS, 2000), many with partly or fully slatted flooring for manure management as slurry. This places limitations on the freedom of movement of the sow and some practical constraints on the types of substrate which can be used to allow expression of nest building behaviour. There has been significant research into developing alternatives to the farrowing crate (for reviews see Baxter et al., 2012; Edwards and Fraser, 1997) but as yet there is no large-scale commercial up-take of a non-crate indoor farrowing system other than in countries where the crate has been prohibited (Sweden, Switzerland and Norway). Constraints preventing voluntary uptake in countries where farrowing crates are permitted include valid farmer concerns about the ability for a loose-housed system to deliver high piglet survival rates, acceptable capital, running and labour costs, efficient labour routines and operator safety (Baxter et al., 2012). There is consequently a need for new alternatives to the farrowing crate that provide maximal sow and piglet welfare whilst addressing these concerns.

The PigSAFE (Piglet and Sow Alternative Farrowing Environment) project aimed to tackle this challenge and developed pen design criteria (based on those summarised in a review by Baxter et al., 2011a) that should provide the correct stimuli required to achieve the desirable outcomes. Since sows show clear preferences for a feeding area separate to both the dunging and nesting areas (Andersen and Pedersen, 2011), the pen incorporates different functional areas: a nest-site with a 
site provides enclosure on three sides, an entrance providing a view into the adjacent pen and a solid floor so that substrate can be provided for nest-building. These criteria were based on sow preference experiments demonstrating the importance of such features (e.g. Cronin et al., 1998; Hunt and Petchey, 1987). Under-floor heating was also installed in the nest-site to offer the possibility of additional thermal support for the newborn piglets and provide a greater temperature differential from the dunging area which might attract sows into the nest for farrowing (Philips et al., 2000; Pedersen et al., 2007). The dunging area was separate and fully slatted to satisfy the sow's preference to dung away from the nest-site (Wiepkema, 1986; Damm and Pedersen, 2000) as well as fulfilling hygiene criteria for the stockworker.

The objective of this experiment was to investigate the sows' use of the designated functional areas in this new pen design, and to address two questions regarding design criteria - namely how much space does the sow require to achieve good performance and whether thermal enhancement of the nest area encourages correct farrowing location and improves piglet survival. It was hypothesised that (i) more space would result in better separation of functional areas and facilitate nest-building behaviour which, since feed-back from the unconstrained performance of nest-building behaviour can affect neuro-endocrine regulation of maternal behaviour (Castrén et al., 1993; Damm et al., 2003; Pedersen et al., 2003; Algers and Uvnäs-Moberg, 2007), would improve subsequent maternal behaviour and piglet survival (Arey et al., 1991; Jensen, 1993; Damm et al., 2003; Pedersen et al., 2003; Yun et al. 2013); and (ii) that a warmer nest floor would be more attractive to farrowing sows and reduce piglet mortality predisposed by perinatal hypothermia (Pedersen et al., 2007).

\section{Materials and methods}

\subsection{Ethical statement}

This study was reviewed and approved by the SRUC Ethical Review Committee (approval ID: ED AE 5/2009). All animal management procedures were adhered to by trained staff.

\subsection{Animals and Housing}

Eighty-eight Landrace $\mathrm{x}$ Large White (Pig Improvement Company, Kingston, Oxfordshire, UK) sows and gilts (hereafter sows; average parity 2.42 ( \pm sem 0.15$)$ ) were randomly selected to take part in this experiment. All animals were housed at the research farm of Scotland's Rural College (SRUC) in 
Midlothian, Scotland. During gestation sows were housed in groups no larger than six per pen. The pens were $3.60 \mathrm{~m} \times 6.25 \mathrm{~m}$, consisting of an enclosed straw-bedded area the rear $(3.60 \mathrm{~m} \times 2.50 \mathrm{~m})$, a central dunging passage $(3.60 \mathrm{~m} \times 1.95 \mathrm{~m})$, and an access passageway plus six individual feeding stalls side by side at the front (each $0.5 \mathrm{~m}$ wide, $1.8 \mathrm{~m}$ long). Sows were fed a standard pregnancy diet, once a day (two kg containing $12.74 \% \mathrm{CP}, 13.32 \mathrm{MJ} \mathrm{DE} . \mathrm{kg}^{-1}$ ). After farrowing, lactation diet $\left(17 \% \mathrm{CP}, 13.75 \mathrm{MJ} \mathrm{DE} . \mathrm{kg}^{-1}\right)$ was offered at a rate of three $\mathrm{kg}$ per day followed by $0.5 \mathrm{~kg}$ increments each day until seven $\mathrm{kg}$ and then followed by one $\mathrm{kg}$ increments each day up to a maximum of $12 \mathrm{~kg}$ until weaning. Throughout, all animals had ad libitum access to water. Approximately five days before their expected due date, sows were weighed, condition scored and had their back-fat thickness measured at the P2 position before being moved into farrowing accommodation (PigSAFE pens). Average pre-farrowing weight, condition score (0-5 scale) and P2 measurements for sows were $258.1 \pm 3.53 \mathrm{~kg}, 3.30 \pm 0.07$ score and $20.91 \pm 0.39 \mathrm{~mm}$ respectively.

PigSAFE (Piglet and Sow Alternative Farrowing Environment) pens had a basic nest area, with solid and insulated concrete flooring to allow provision of nesting material. For nesting, $2 \mathrm{~kg}$ of longstemmed straw was maintained by daily replenishment (not cumulative) from day -5 . This level was maintained until day +7 and then it was reduced to $1 \mathrm{~kg}$ of straw daily until weaning. The nest was equipped with sloping walls against which the sow can slide more slowly to ground level for suckling, which had a gap between their base and the floor to lower the risk of piglets being trapped and killed. A heated, corner creep area $\left(0.75 \mathrm{~m}^{2}\right)$ with easy access from the nest was bedded with a thin layer of sawdust. The solid nest area was equipped with under-floor heating which could be adjusted on a pen by pen basis (see section 2.3 Experimental Design for temperature settings). A separate slatted dunging area (Triband metal $9 \mathrm{~mm}$ void) was bounded by walls with barred panels to adjacent pens to discourage farrowing outside the nest and allow visual and oral-nasal contact between neighbouring sows. A feeding stall for the sow $(0.50 \mathrm{~m}$ wide, bounded by solid sides) was included at one side of the pen, where the sow could be locked in to allow safe inspection or treatment of the piglets. This basic prototype pen design was adapted to determine the influence of space and temperature on farrowing location, maternal behaviour and piglet survival (Figure 1a and b).

\subsection{Experimental design}

The sows were randomly assigned to treatment groups in a $2 \times 2$ factorial design to test the influence of space and nest floor temperature on farrowing location and maternal behaviour. The sows were either assigned to the LARGE space treatment $\left(9.7 \mathrm{~m}^{2}\right.$ in total; dunging passage $=2.20 \mathrm{~m} \times 1.60 \mathrm{~m}$, 
nest-site $=1.30 \mathrm{~m} \times 2.80 \mathrm{~m})$ or the SMALL space treatment $\left(7.9 \mathrm{~m}^{2}\right.$ in total; dunging passage $=2.20 \mathrm{~m} \times$ $1.23 \mathrm{~m}$, nest-site $=0.90 \mathrm{~m} \times 2.38 \mathrm{~m})$. The nest-site floor was heated to either $20^{\circ} \mathrm{C}(\mathrm{T} 20)$ or $30^{\circ} \mathrm{C}(\mathrm{T} 30)$ from $48 \mathrm{~h}$ before until $24 \mathrm{~h}$ after farrowing. Figure 1 illustrates the experimental pens side-by-side. The overall farrowing room temperature was set at $18^{\circ} \mathrm{C}$ for the first week during and after farrowing, before being reduced to approximately $16^{\circ} \mathrm{C}$ for the remainder of lactation. Creep temperatures were set at $30^{\circ} \mathrm{C}$ for farrowing and the first week post-farrowing before being set on a curve gradually reducing the temperature to approximately $25^{\circ} \mathrm{C}$ for the remainder of lactation.
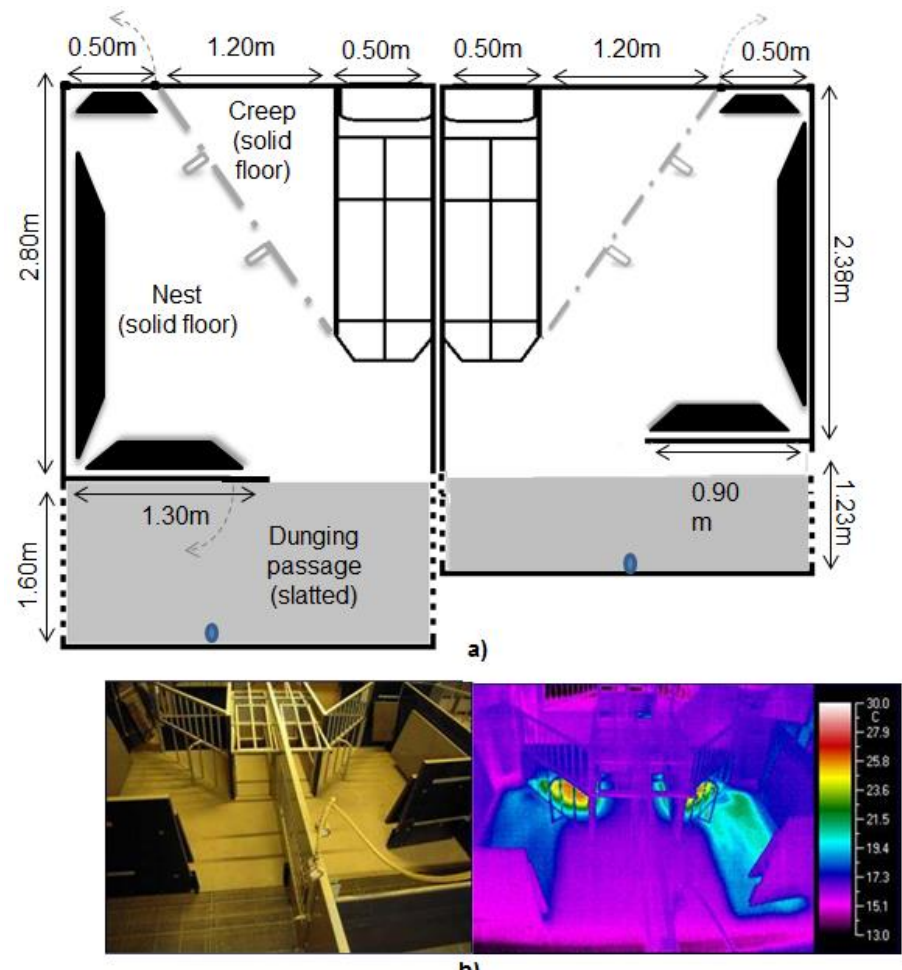

KEY:

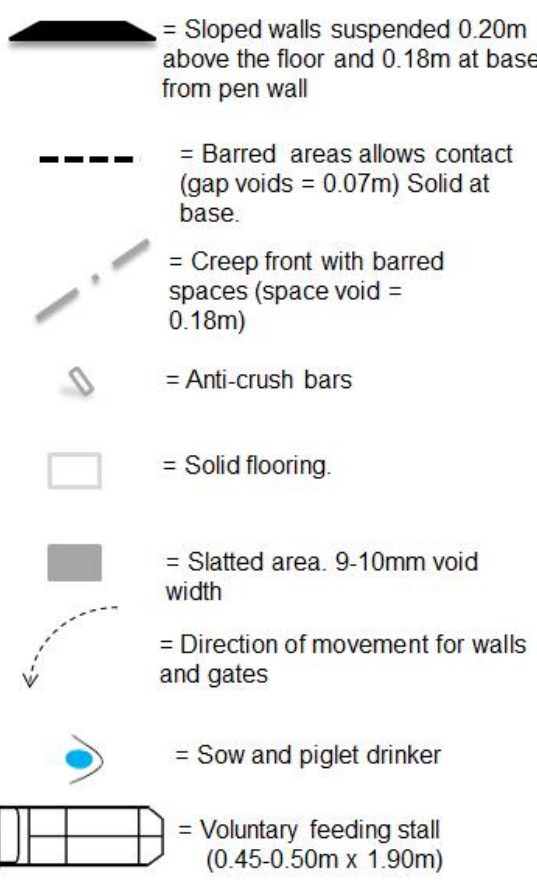

145 Figure 1. a) Prototype PigSAFE pens (not to scale) side-by-side showing the LARGE and SMALL space treatments and $\mathrm{b})$ the under-floor heating treatments $\mathrm{T} 20\left(20^{\circ} \mathrm{C}\right)$ and $\mathrm{T} 30\left(30^{\circ} \mathrm{C}\right)$.

\subsection{Data collection}

Piglet mortality was recorded with post-mortem examination confirming cause of death. Video cameras (Low-lux B/W waterproof cameras: SK-2020XC/SO, RF Concepts Ltd, Belfast, Ireland) captured continuous data from all pens from day -5 until at least day +2 post farrowing. Farrowing kinetics (cumulative farrowing duration and average birth interval) were recorded. Of particular interest in this study was where in the pen sows chose to farrow and the quality of maternal behaviour in terms of posture changes during farrowing. These data were collected for 84 of the 
followed for $24 \mathrm{~h}$ after the birth of the first piglet to record crushing incidents (both injurious and non-injurious - see Table 1 for full ethogram). One sow and her litter had to be excluded from analysis of performance and behaviour at $24 \mathrm{~h}$ post-partum because the piglets contracted alloimmune thrombocytopenia after ingestion of their mother's colostrum. As the condition only manifested itself in the piglets post-farrowing, the sow's farrowing location data were included for analysis. For farrowing location analysis, the pen was divided into seven areas (L1-L7). L1 was designated as the preferred farrowing location based on the fact that if sows farrowed in this location piglets would be born closest to the creep area and furthest from the dunging passage which was designated as L7. L7 was designated the least preferred farrowing location as it contained no piglet protection features or bedding and had no additional heating source for the piglets (Figure 2).

Table 1. Ethogram describing the type of crushing behaviour displayed by sows

\begin{tabular}{|l|l|}
\hline Sow crush behaviour & Description \\
\hline Stand-to-Walk & $\begin{array}{l}\text { Sow puts prolonged pressure (defined as more than } 2 \text { seconds) on the piglet } \\
\text { by stepping or sow kicks the piglet whilst walking }\end{array}$ \\
\hline Sit-to-Lie & $\begin{array}{l}\text { Sow puts prolonged pressure on the piglet when moving from a sitting } \\
\text { posture to lying down. Piglets can get trapped underneath the sow's } \\
\text { sternum }\end{array}$ \\
\hline Stand-to-Lie & $\begin{array}{l}\text { Sow puts prolonged pressure when moving from a standing posture to lying } \\
\text { down. Sow may kneel before dropping her flank either to the side into a } \\
\text { lateral* lying posture or straight down into ventral* }\end{array}$ \\
\hline Roll & $\begin{array}{l}\text { Sow puts prolonged pressure on the piglet whilst rolling from a ventral lying } \\
\text { posture to a lateral lying posture or sow is already lying laterally but } \\
\text { stretches to fully expose her udder and traps a piglet }\end{array}$ \\
\hline Stand-to-Sit & $\begin{array}{l}\text { Sow puts prolonged pressure by moving from a standing to a sitting posture } \\
\text { by lowering rear directly down without kneeling }\end{array}$ \\
\hline Clamp & $\begin{array}{l}\text { Sow puts prolonged pressure on a piglet by trapping it with her leg when } \\
\text { lying in a fully lateral position. Piglets can get clamped between the two back } \\
\text { legs or crushed between a leg and a pen fitting. }\end{array}$ \\
\hline
\end{tabular}


175 The number of sows in each treatment was unbalanced (SMALL_T20 $n=21$; SMALL_T30 $n=23$; 176 LARGE_T20 n = 22; LARGE_T30 $n=22$ ), thus Generalised Linear Mixed Models (GLMM) were fitted 177 to the data (Genstat $14^{\text {th }}$ edition) for analysis of mortality, farrowing location, farrowing kinetics, and 178 number of posture changes during farrowing. A binomial distribution with a logit link function was 179 fitted to a GLMM to analyse the influence of space and temperature (fitted as fixed effects) on 180 mortality (i.e. piglets were either dead (1) or alive (0) for the binomial model) and the sows' location 181 to farrow the first piglet in the litter. These location data were categorical (i.e. 1-7 possible 182 locations), therefore the fixed estimate of binomial totals was set at 7. A Poisson distribution, with a 183 logarithm link function was fitted to GLMMs to analyse the influence of space and temperature on 184 the location where the remaining piglets were farrowed. In all models parity was fitted as a fixed effect and sow was fitted as a random factor. When necessary, cross-fostering was performed (only within the first $48 \mathrm{~h}$ post-partum) and the subsequent mortality data were adjusted accordingly to reflect the fostered litter size.

In order to analyse each separate location by treatment, non-parametric tests (Mann-Whitney U Genstat $14^{\text {th }}$ edition) had to be used as there were a large number of values returned as zero. The differences between treatments regarding type of crushing behaviour by the sow also returned a large number of zeros therefore were analysed using non-parametric tests (Chi-square and MannWhitney U).

\section{Results}

\subsection{Farrowing location}

The majority of sows commenced farrowing in the L1 position (56\%). However sows changed position during farrowing, with only a further $39 \%$ of total piglets born in this location. Ninety-seven percent of total piglets were born in the nest with dunging passage farrowings very rare (Figure 2). 
a) Percentage of sows initating farrowing in each location

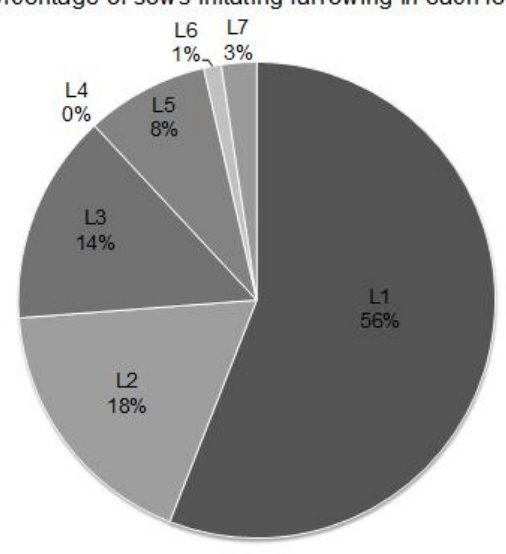

b) Percentage of all piglets farrowed in specific location

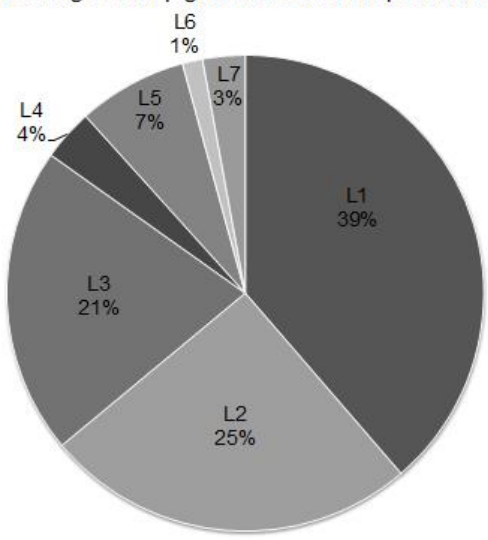

Key:

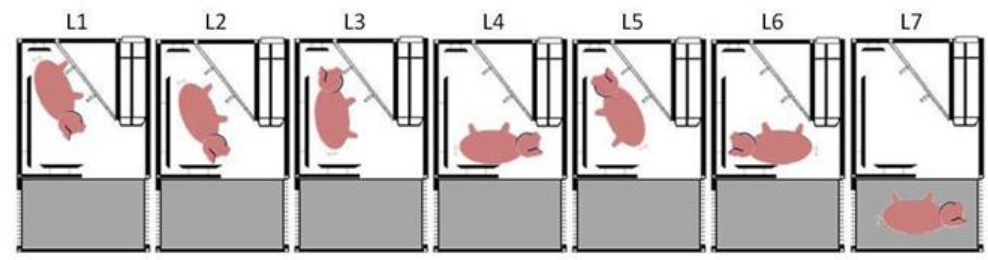

204 Figure 2: Farrowing location for a) percentage of all first born piglets and b) percentage of all piglet births. Possible farrowing locations in PigSAFE pens (not to scale) illustrated below pie-charts. L1 considered the optimum farrowing location for piglet survival.

208 Temperature and space treatments had no effect on where sows chose to start farrowing $\left(F_{1,80}=\right.$ $2090.00, P=0.986$ and $F_{1,80}=0.52, P=0.474$ respectively) or where they chose to farrow the remainder of 210 their litter $\left(F_{1,556}=0.09, P=0.763\right.$ and $F_{1,556}=0.01, P=0.941$ respectively $)$, however the small number of 211 sows that farrowed in the dunging area (3\%; four sows farrowed $13 \%, 20 \%, 86 \%$ and $100 \%$ of their 212 litter respectively in L7; two of these sows started farrowing in L7) were from the SMALL_T20 213 treatment. Overall there were significant differences in percentage of piglets farrowed in each 214 location $\left(F_{6,556}=11.96, P<0.001\right)$ with a significant space $x$ temperature interaction for farrowing 215 location $\left(F_{6,556}=2.80, P=0.011\right)$. Figure 3 summarises the interactive effects illustrating that the 216 combination of the smaller space and the T20 temperature achieved the most L1 farrowing 217 positions.

218 


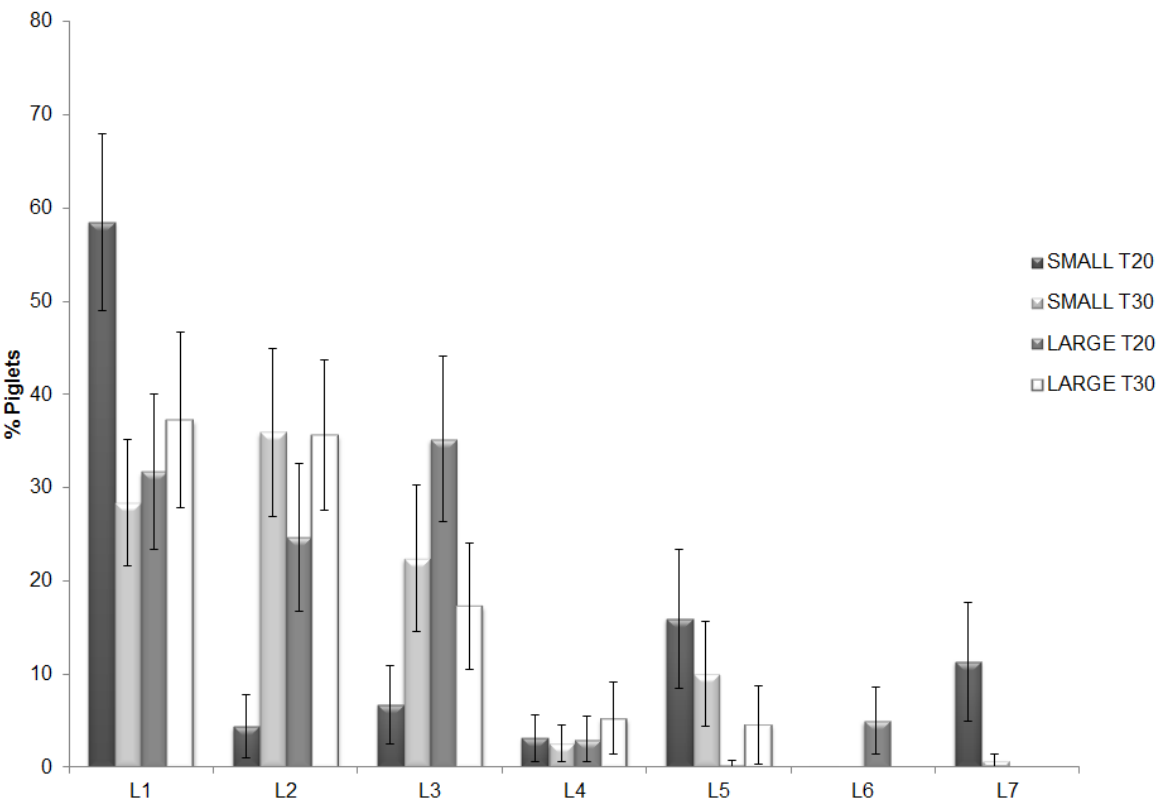

221 Figure 3. Interactive effects of space and temperature on the areas where piglets were farrowed in PigSAFE pens.

224 Table 2 summarises differences at each location for the separate treatments and shows that 225 significantly more piglets were born in L5 and L7 in the SMALL treatment compared with the LARGE 226 (Table 2. L5: SMALL $=12.97 \%$ vs. LARGE $=2.37 \% P=0.04$ and $L 7:$ SMALL $=6.02 \%$ vs. $L A R G E=0.00 \%$ $227 \quad P<0.001)$. The only significant difference within the temperature treatment came at $\mathrm{L} 2$ where more 228 piglets were born in this location in the T30 temperature (Table 2. T20 $=15.25 \%$ vs. T30 $=35.79 \%$ $229 P=0.006)$.

230

\subsection{Performance}

232

233 Eight-eight sows produced 1109 piglets; average litter size was 12.75 ( \pm 0.41$)$, with $11.97( \pm 0.40)$ 234 born alive and $0.78( \pm 0.14)$ born dead (intra-partum stillbirths). 
Table 2: Percentage of piglets per litter ( \pm SEM) born in each location in SMALL $\left(7.9 \mathrm{~m}^{2}\right)$ or LARGE $\left(9.7 \mathrm{~m}^{2}\right)$ PigSAFE farrowing pens with T20 $\left(20^{\circ} \mathrm{C}\right)$ or T30 $238\left(30^{\circ} \mathrm{C}\right)$ under-floor heating temperatures. Figures given as means $( \pm \mathrm{sem})$ and medians to demonstrate descriptive data.

\begin{tabular}{|c|c|c|c|c|c|c|c|c|c|c|c|c|}
\hline \multirow{3}{*}{ Location } & \multicolumn{6}{|c|}{ Space (S) } & \multicolumn{6}{|c|}{ Temperature $(\mathrm{T})$} \\
\hline & \multicolumn{2}{|c|}{ SMALL $(n=40)$} & \multicolumn{2}{|c|}{ LARGE $(n=44)$} & \multirow[b]{2}{*}{ U-stat ${ }^{1}$} & \multirow[b]{2}{*}{ P-value } & \multicolumn{2}{|c|}{$T 20(n=42)$} & \multicolumn{2}{|c|}{$T 30(n=42)$} & \multirow[b]{2}{*}{$\mathbf{U}^{1}$-stat } & \multirow[b]{2}{*}{ P-value } \\
\hline & $\begin{array}{l}\text { Mean } \\
\text { (tsem) }\end{array}$ & $\begin{array}{l}\text { Median } \\
\text { (range) }\end{array}$ & $\begin{array}{l}\text { Mean } \\
\text { ( } \pm \text { sem) }\end{array}$ & $\begin{array}{l}\text { Median } \\
\text { (range) }\end{array}$ & & & $\begin{array}{l}\text { Mean } \\
\text { ( } \pm \text { sem) }\end{array}$ & $\begin{array}{l}\text { Median } \\
\text { (range) }\end{array}$ & $\begin{array}{l}\text { Mean } \\
\text { ( } \pm \text { sem) }\end{array}$ & $\begin{array}{l}\text { Median } \\
\text { (range) }\end{array}$ & & \\
\hline L1 & $\begin{array}{c}43.44 \\
( \pm 6.24)\end{array}$ & $\begin{array}{c}35.42 \\
(0-100)\end{array}$ & $\begin{array}{r}34.35 \\
( \pm 6.20)\end{array}$ & $\begin{array}{c}10.48 \\
(0-100)\end{array}$ & 741 & 0.201 & $\begin{array}{c}44.16 \\
( \pm 6.53)\end{array}$ & $\begin{array}{c}23.21 \\
(0-100)\end{array}$ & $\begin{array}{c}32.93 \\
( \pm 5.82)\end{array}$ & $\begin{array}{c}21.54 \\
(0-100)\end{array}$ & 765 & 0.283 \\
\hline L2 & $\begin{array}{c}20.17 \\
( \pm 5.37)\end{array}$ & $\begin{array}{c}0.00 \\
(0-100)\end{array}$ & $\begin{array}{c}29.93 \\
( \pm 5.66)\end{array}$ & $\begin{array}{c}7.69 \\
(0-100)\end{array}$ & 738 & 0.165 & $\begin{array}{c}15.25 \\
( \pm 4.74)\end{array}$ & $\begin{array}{c}0.00 \\
(0-100)\end{array}$ & $\begin{array}{c}35.79 \\
( \pm 5.96)\end{array}$ & $\begin{array}{c}24.04 \\
(0-100)\end{array}$ & 601 & 0.006 \\
\hline L3 & $\begin{array}{c}14.56 \\
( \pm 4.57)\end{array}$ & $\begin{array}{c}0.00 \\
(0-100)\end{array}$ & $\begin{array}{c}26.66 \\
( \pm 5.76)\end{array}$ & $\begin{array}{c}0.00 \\
(0-100)\end{array}$ & 716 & 0.098 & $\begin{array}{c}21.94 \\
( \pm 5.54)\end{array}$ & $\begin{array}{c}0.00 \\
(0-100)\end{array}$ & $\begin{array}{c}19.80 \\
( \pm 5.11)\end{array}$ & $\begin{array}{c}0.00 \\
(0-100)\end{array}$ & 865 & 0.867 \\
\hline L4 & $\begin{array}{c}2.84 \\
( \pm 1.60)\end{array}$ & $\begin{array}{c}0.00 \\
(0-50)\end{array}$ & $\begin{array}{c}4.08 \\
( \pm 2.21)\end{array}$ & $\begin{array}{c}0.00 \\
(0-80)\end{array}$ & 864 & 0.682 & $\begin{array}{c}3.08 \\
( \pm 1.72)\end{array}$ & $\begin{array}{c}0.00 \\
(0-53.3)\end{array}$ & $\begin{array}{c}3.92 \\
( \pm 2.19)\end{array}$ & $\begin{array}{c}0.00 \\
(0-80)\end{array}$ & 863 & 0.867 \\
\hline L5 & $\begin{array}{c}12.97 \\
( \pm 4.65)\end{array}$ & $\begin{array}{c}0.00 \\
(0-100)\end{array}$ & $\begin{array}{c}2.37 \\
( \pm 2.00)\end{array}$ & $\begin{array}{c}0.00 \\
(0-87.5)\end{array}$ & 735 & 0.040 & $\begin{array}{c}7.61 \\
( \pm 3.65)\end{array}$ & $\begin{array}{c}0.00 \\
(0-100)\end{array}$ & $\begin{array}{c}7.22 \\
( \pm 3.46)\end{array}$ & $\begin{array}{c}0.00 \\
(0-87.5)\end{array}$ & 879 & 0.907 \\
\hline L6 & $\begin{array}{c}0.00 \\
( \pm 0.00)\end{array}$ & $\begin{array}{l}0.00 \\
(0-0)\end{array}$ & $\begin{array}{c}2.61 \\
( \pm 1.91)\end{array}$ & $\begin{array}{c}0.00 \\
(0-75)\end{array}$ & 840 & 0.543 & $\begin{array}{c}2.67 \\
( \pm 1.96)\end{array}$ & $\begin{array}{c}0.00 \\
(0-75)\end{array}$ & $\begin{array}{c}0.00 \\
( \pm 0.00)\end{array}$ & $\begin{array}{l}0.00 \\
(0-0)\end{array}$ & 840 & 0.494 \\
\hline L7 & $\begin{array}{c}6.02 \\
( \pm 3.27)\end{array}$ & $\begin{array}{c}0.00 \\
(0-100)\end{array}$ & $\begin{array}{c}0.00 \\
( \pm 0.00)\end{array}$ & $\begin{array}{l}0.00 \\
(0-0)\end{array}$ & 748 & $<0.001$ & $\begin{array}{c}5.27 \\
( \pm 3.05)\end{array}$ & $\begin{array}{c}0.00 \\
(0-100)\end{array}$ & $\begin{array}{c}0.35 \\
( \pm 0.35)\end{array}$ & $\begin{array}{c}0.00 \\
(0-14.3)\end{array}$ & 798 & 0.114 \\
\hline
\end{tabular}

${ }^{1}$ Mann-Whitney $U$ tests carried out on raw percentage data and used to show whether there was a significant effect of space or temperature. 
241 The $2 \times 2$ structured comparison showed that the floor temperature at the time of farrowing had no 242 significant influence on piglet survival (Total mortality: T20 $=19.01 \%$ ( \pm sem2.41) vs. T30 $=19.81 \%$ 243 ( \pm sem3.05) $\mathrm{F}_{1,86}=0.71, P=0.401$; Live-born mortality: $\mathrm{T} 20=13.07 \%$ ( \pm sem2.30) vs. T30 $=16.01 \%$ 244 ( \pm sem2.96) $F_{1,86}=0.05, P=0.826$ ). However the amount of space influenced live-born mortality, with 245 significantly more piglets dying when sows were afforded a larger farrowing space (Live-born 246 mortality: $L A R G E=18.10 \%\left( \pm\right.$ sem2.30) vs. SMALL $=10.90 \%\left( \pm\right.$ sem2.92) $\left.F_{1,86}=5.00, P=0.028\right)$. This was 247 reflected in a tendency for greater total mortality when sows were afforded the larger space (Total248 mortality: $L A R G E=23.14 \%\left( \pm\right.$ sem2.34) vs. SMALL $=15.68 \%\left( \pm\right.$ sem3.05) $\left.F_{1,86}=2.86, P=0.095\right)$. There 249 were no significant interactions between space and temperature for either total mortality 250 (SMALL_T20 $=16.05 \%$ ( \pm sem3.27), SMALL_T30 $=15.31 \%( \pm$ sem5.10), LARGE_T20 $=21.97 \%$ 251 ( \pm sem3.50), LARGE_T30 $=24.31 \%\left( \pm\right.$ sem3.13) $\left.\mathrm{F}_{1,86}=0.74, P=0.394\right)$ or live-born mortality (SMALL_T20 $252=9.73 \%( \pm$ sem2.96), SMALL_T30 $=12.07 \%( \pm$ sem5.03), LARGE_T20 $=16.42 \%( \pm$ sem3.47), LARGE_T30 $253=19.96 \%$ ( \pm sem3.09) $F_{1,86}=0.17, P=0.685$ ). Crushing was the largest cause of mortality (42\%); 254 however there was a great deal of individual variation with some sows showing a high propensity to 255 crush whilst others achieved 100\% survival (Figure 4).

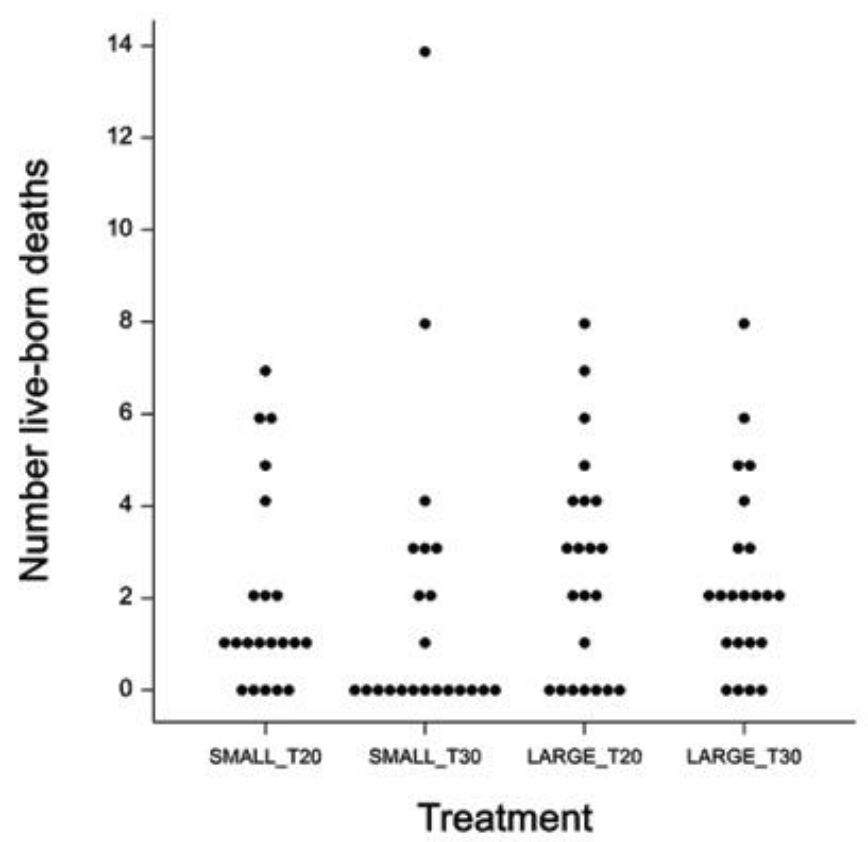

a)

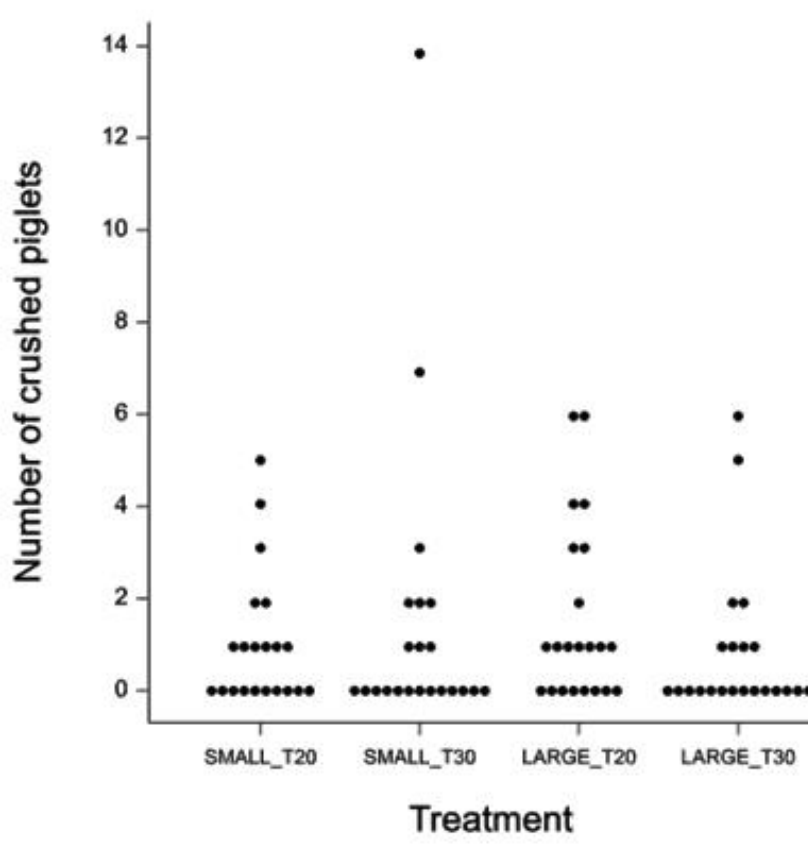

b)

258 Figure 4: Differences in a) number of live-born deaths and b) crushes by individual sows in each 


\subsection{Maternal behaviour}

262

263

\subsubsection{Farrowing kinetics and behaviour}

264

There were no interactive effects of space and temperature on farrowing kinetics (cumulative 265 farrowing duration (mins): SMALL_T20 = 199.9 ( \pm 15.95$)$; SMALL_T30 = $279.6( \pm 25.86) ;$ LARGE_T20 = 302.2 ( \pm 73.27$) ;$ LARGE_T30 $=279.0( \pm 45.79) ; F_{1,86}=1.00, P=0.320$ and average birth interval (mins) SMALL_T20 = $19.02( \pm 2.03) ;$ SMALL_T30 $=24.19( \pm 2.34) ;$ LARGE_T20 $=23.80( \pm 5.34) ;$ LARGE_T30 = $\left.25.85( \pm 4.16) ; F_{1,86}=0.38, P=0.451\right)$. However the higher floor temperature resulted in longer average posture changes sows performed during farrowing (SMALL_T20 $=25.87( \pm 4.37)$; SMALL_T30 $=28.91$ $( \pm 4.47) ;$ LARGE_T20 $=25.27( \pm 3.28) ;$ LARGE_T30 $\left.=27.66( \pm 6.80): F_{1,86}=1.06, P=0.306\right)$.

272

\subsubsection{Crushing behaviour}

274

275 Of the sub-set of sows that were observed for $24 \mathrm{~h}$ from the birth of the first piglet $53 \%(n=27)$ of 276 them showed some type of crushing behaviour. Since there was no influence of temperature on 277 mortality, only the influence of space on type of crush was analysed. There were significantly more 278 crushing incidents when sows were afforded the larger space $\left(X^{2}{ }_{6}=35.85, P<0.001\right)$. This treatment 279 yielded a greater total number of observed rolling, clamping and kicking (i.e. when the sow 280 transitions from standing to walking) events (Table 3). Mann Whitney $U$ tests revealed that a significant difference existed only for the kicking category, indicating that the numerical differences between space treatments regarding rolling and clamping events were attributable to a small number of sows within the treatments. Stand to sit crushing incidences were rare but were only observed in the SMALL space treatment (Table 3). 
Table 3. Types of crushing incident in the SMALL and LARGE space treatments. Figures given as total and median number of incidents for sows that showed crushing behaviour, during $24 \mathrm{~h}$ from the birth of the first piglet. Mann-Whitney $\mathrm{U}$ tests determine where differences lie.

\begin{tabular}{|l|c|c|c|c|c|c|}
\hline \multirow{2}{*}{} & \multicolumn{2}{|c|}{ Total number } & \multicolumn{2}{c|}{ Medians } & & \\
\cline { 2 - 7 } & $\begin{array}{c}\text { SMALL } \\
(\mathbf{n = 1 1})\end{array}$ & $\begin{array}{c}\text { LARGE } \\
(\mathbf{n}=\mathbf{1 6})\end{array}$ & $\begin{array}{c}\text { SMALL } \\
(\text { range) }\end{array}$ & $\begin{array}{c}\text { LARGE } \\
(\text { range) }\end{array}$ & U-stat & P-value \\
\hline Clamp & 0 & 13 & $\begin{array}{c}0 \\
(0-0)\end{array}$ & $\begin{array}{c}0 \\
(0-9)\end{array}$ & 71.5 & 0.383 \\
\hline Stand-to-lie & 20 & 17 & $\begin{array}{c}2 \\
(0-6)\end{array}$ & $\begin{array}{c}1 \\
(0-3)\end{array}$ & 67.0 & 0.284 \\
\hline Sit-to-lie & 8 & 9 & $\begin{array}{c}0 \\
(0-2)\end{array}$ & $\begin{array}{c}0 \\
(0-2)\end{array}$ & 81.0 & 0.704 \\
\hline Stand-to-walk & 0 & 17 & $\begin{array}{c}0 \\
(0-0)\end{array}$ & $\begin{array}{c}0.5 \\
(0-4)\end{array}$ & 44.0 & 0.012 \\
\hline Roll (ventral to lateral) & 1 & 11 & $\begin{array}{c}0 \\
(0-1)\end{array}$ & $\begin{array}{c}0 \\
(0-7)\end{array}$ & 73.0 & 0.406 \\
\hline Lie-to-sit & 1 & 4 & $\begin{array}{c}0 \\
(0-1)\end{array}$ & $\begin{array}{c}0 \\
(0-2)\end{array}$ & 79.0 & 0.734 \\
\hline Stand-to-sit & 4 & 0 & $\begin{array}{c}0 \\
(0-2)\end{array}$ & $\begin{array}{c}0 \\
(0-0)\end{array}$ & 64.0 & $<0.001$ \\
\hline
\end{tabular}

\section{Discussion}

293

\subsection{Farrowing location}

295

Sows showed a clear preference to farrow in the nest area regardless of the different space or temperature treatments. Heating the floor did not alter the attractiveness of the nest area for farrowing. It is likely that the design of the PigSAFE pen provided sufficient stimuli to encourage the sow to farrow in the nest area without the additional heat source. These stimuli included provision of enclosure by solid walls, sufficient substrate with which to satisfy nest-building behaviour and suitable flooring to maintain the nest. In early work looking at nest-site choice of sows, Hunt and Petchey (1987) demonstrated clear preferences for farrowing inside, or against a solid wall. Similar choices were shown by sows under natural and semi-natural conditions (Stolba and Wood-Gush, 1984) where $40 \%$ chose total enclosure and $89 \%$ chose partial enclosure. The nest opening in the PigSAFE pen permits sows the ability to see their neighbour's pen and this added motivation to face the nest entrance is likely to have further influenced the sow's decision to farrow in the L1 location within the nest, since sows in the wild select nest sites allowing them to maintain vigilance for approaching threats (Stolba and Wood-Gush, 1984). In the current study the majority of sows 
started farrowing in this position which is considered optimal in the PigSAFE pen because the birth

310 site is furthest away from the cooler and unprotected slatted dunging area and the udder when lying 311 laterally is immediately adjacent to the creep. Within minutes of being born piglets stand and 312 perform teat seeking behaviours (Rohde and Gonyou, 1987). If sows are lying in the L1 position in 313 the PigSAFE pen, piglets will walk in front or through the heated creep to access the udder, which 314 could promote early use of this warmed and protected area. It is generally thought that piglets 315 remain in close proximity to the udder within the first 2-3 days post-partum, although there is large 316 variation between litters studied (Berg et al., 2006; Vasdal et al., 2010). Proximity to the udder brings 317 warmth, develops teat fidelity for better colostrum and milk intake but also brings greater risk of 318 crushing by the sow (Weary et al., 1996a). In a loose farrowing environment in particular, it is 319 advantageous to attract the piglets into a protected area as quickly as possible (outwith the periods 320 of suckling). Opposite the creep the nest wall is sloped with specific dimensions to protect piglets 321 from being crushed when sows descend from standing to lying or roll against the pen side. The 322 sloped wall also prevents piglets from being blocked when teat-seeking, providing a protected 323 tunnel if they choose to walk around the sow. Sow preferences to use such supportive structures 324 have been demonstrated in the past (Baxter, 1991; Damm et al., 2006; Marchant et al., 2001) and 325 providing these structures in this pen design appears to have aided optimal farrowing position.

327 There were significant treatment effects on farrowing location, with the combination of the smaller space and the lower under-floor temperature of $20^{\circ} \mathrm{C}$ achieving the most $\mathrm{L} 1$ births. Although there is evidence that sows prefer warmer areas in which to farrow and certainly seek them post-partum (Pedersen et al., 2007; Phillips et al., 2000), the current study does not support this preference. However the nest-site may have provided adequate thermal stimuli in all treatments, since $2 \mathrm{~kg}$ of long-stemmed straw (known to reduce heat loss - Mount, 1967) was provided on a solid, insulated concrete floor heated to a minimum of $20^{\circ} \mathrm{C}$. It thus provided a microclimate with less thermal conductivity than the slatted dunging area, and the nest-site enclosure with a narrow nest entrance also reduced air movement.

337 Some sows did choose to vary their farrowing positions and there was greater variability evident in 338 the smaller space. The greater number of L5 births in the smaller space seemed to reflect the fact 339 that this position was often adopted for the second born in the litter, with sows starting the 340 farrowing process in L1 then getting up and inspecting their piglet before lying back down facing 341 their first piglet and continuing the farrowing process. Dunging passage farrowings were very rare; 342 however the two sows that did commence farrowing at this location were both housed in the small 
space. Extra space in the large pen may create a much clearer distinction between the two areas for 344 the sows.

\subsection{Performance}

348 The larger space resulted in higher piglet mortality, despite farrowings taking place in the nest and 349 the nest having the same design features in both treatments. The sow was afforded greater unobstructed floor space in the larger nest and could lie down unsupported if she chose. In addition she could roll without contacting the supportive structures. Rolling from a ventral to a lateral lying position is a known risk factor for crushing in loose-housed systems (Weary et al., 1996b; Damm et al., 2005; Danholt et al., 2011) and the descriptive data for types of crush saw sows farrowing in the larger space showing greater total crushing incidents involving rolling, although these incidences were confined to only a few of the sows.

The other risk with a larger nest space is that piglets have a greater area in which to wander and become chilled when distant from heat sources. When sows have suitable floor-type and sufficient materials with which to build a nest, they will often dig a hollow depression, fill it with substrates like grasses, mosses and leaves and surround it with larger branches and twigs (reviewed in Wischner et al., 2009). The nest is thus an oval shape designed to keep the piglets close and offer thermal protection. Such nest construction is limited in a farm setting. There was a tendency for a greater number of farrowings in the L3 position in the larger space. Although this is still in the nest-site, piglets were born further away from the creep with closer proximity to the dunging area and therefore a greater risk of hypothermia. Cronin et al. (Cronin and Smith, 1992; Cronin et al., 1994), in their development of the Werribee Farrowing Pen, also demonstrated that too large a nest site increases mortality, especially in cooler ambient temperatures, suggesting that piglet thermal protection can interact with nest size. However, these authors also demonstrated the importance of providing a nest of sufficient width to allow performance of behaviours that influence piglet survival, notably nest-building and suckling (Cronin et al., 1998).

372 The current study has demonstrated the problems associated with affording too much space in the 373 area to be shared by the piglets. The small space was sufficient to facilitate nest-building because it 374 provided a greater planar width and length at the sow's shoulder height compared with the space 375 provided at the floor level, making turning around easier, and provided a separate dunging area 376 giving additional space for activity. The nest dimensions were proposed by Baxter et al. (2011a) after 
their review of space requirements for farrowing and lactation systems based on body dimensions of modern sows (Moustsen et al., 2011). However, experience during this study, where large sows were frequently observed with their udders compressed against the creep bars, would recommend an extra $20 \mathrm{~cm}$ width to the pens, to accommodate unimpeded suckling for all litters.

\subsection{Maternal behaviour}

383

384

In this study higher floor temperatures resulted in longer piglet inter-birth intervals. A similar result 385 was observed by Malmkvist et al. (2012), but was correlated with length of time the under-floor heating was on before farrowing. Neither these authors nor the current study found a negative relationship with survival, however prolonged farrowings and heat stress in sows do have the potential for negative outcomes for both sows and piglets (e.g. Prunier et al., 1997; Edwards, 2002), particularly in restrictive environments where the sows are unable to regulate their body temperature via behavioural adaptations (Malmkvist et al., 2012).

Regardless of space or temperature treatments, there was great variability between sows in piglet mortality and in crushing behaviour, with number of crushed piglets per litter ranging from 0-14. Given the importance of maternal behaviour to piglet survival in loose-housed farrowing systems (Arey, 1997), this variability could be key in whether or not loose-farrowing accommodation becomes more commercially viable. Since maternal behaviour has been shown to have a genetic component (Grandinson et al., 2003; Gäde et al., 2008), investigating the consistency and possibility for change in important maternal behaviours such as carefulness (e.g. pre-lying behaviour, offspring communication and maternal responsiveness - Weschler and Hegglin, 1997; Valros et al., 2003; Illmann et al., 2008), aggression (e.g. offspring-directed - Chen et al., 2007; Baxter et al., 2011b, and stock-person directed- Marchant-Forde, 2002) and temperament (e.g. fearfulness - Thodberg et al., 2002) in the environment in which the animals will be kept is an area meriting further investigation.

\subsection{Conclusions}

405

Designing a farrowing environment that optimises both sow and piglet welfare involves providing adequate freedom of movement for the sow, in conjunction with the correct stimuli to promote good maternal behaviour (e.g. correct farrowing location) and suitable protection (thermal and physical) for piglets. This study has provided quantitative information on specific design criteria required in a loose farrowing and lactation system and demonstrated the importance of design 
detail such as dimensions of specific functional areas. Individual variation in maternal behaviour

412 influences consistency of performance in loose-housed systems and their potential for further

413 commercial adoption. Investigating the possibilities of selecting sows for specific loose-farrowing

414 traits should be a target in this area of research.

415

416

\section{Acknowledgements}

418

419 The authors wish to thank technical and farm staff for assistance with the project. The authors are

420 grateful to the Department for Environment, Food and Rural Affairs (Defra) of the UK for funding the

PigSAFE project (AW0143). Authors also receive funding from the Scottish Government.

422

423

References

424

Algers, B. and Uvnäs-Moberg, K. 2007. Maternal behavior in pigs. Hormones and Behavior 52, 78-85.

425

426

427

428

429

430

431

432

433

434

435

436

437

438

439

440

441

Andersen, H.M.L. and Pedersen, L.J., 2011. The effect of feed trough position on choice of defecation area in farrowing pens by loose sows. Applied Animal Behaviour Science 131: 48-52.

Arey, D.S., Petchey, A.M. and Fowler, V.R. 1991. The preparturient behavior of sows in enriched pens and the effect of preformed nests. Applied Animal Behaviour Science 31, 61-68.

Arey, D.S. 1997. Behavioural observations of peri-parturient sows and the development of alternative farrowing accommodation: A review. Animal Welfare 6(3), 217-229

Baxter, E.M., Lawrence, A.B., Edwards, S.A., 2011a. Alternative farrowing systems: design criteria for farrowing systems based on the biological needs of sows and piglets. Animal 5, 580-600.

Baxter, E.M., Jarvis, S., Sherwood, L., Farish, M., Roehe, R., Lawrence, A.B. and Edwards, S.A. 2011b. Genetic and environmental effects on piglet survival and maternal behaviour of the farrowing sow. Applied Animal Behaviour Science 130, 28-41.

Baxter, E.M., Lawrence, A.B., Edwards, S.A., 2012. Alternative farrowing accommodation: welfare and economic aspects of existing farrowing and lactation systems for pigs. Animal 6, 96-117.

Baxter, M.R., 1991. The Freedom Farrowing System. Farm Building Progress, 9-15.

Berg, S., Andersen, I.L., Tajet, G.M., Haukvik, I.A., Kongsrud, S., Boe, K.E., 2006. Piglet use of the creep area and piglet mortality - effects of closing the piglets inside the creep area during sow feeding time in pens for individually loose-housed sows. Animal Science 82, 277-281. 
Castrén, H., Algers, B., de Passillé, A-M., Rushen, J. and Uvnäs-Moberg, K. 1993. Preparturient variation in progesterone, prolactin, oxytocin and somatostatin in relation to nest building in sows. Applied Animal Behaviour Science 38, 91-102.

Chen, C., Gilbert, C.L., Yang, G., Guo, Y., Segonds-Pichon, A., Ma,J., Evans, G., Brenig, B., Sargent, C., Affara, N. and Huang, L. 2007. Maternal infanticide in sows: Incidence and behavioural comparisons between savaging and non-savaging sows at parturition. Applied Animal Behaviour Science 109, 238-248

Cronin, G.M. and Smith, J.A. 1992. Effects of accommodation type and straw bedding around parturition and during lactation on the behavior of primiparous sows and survival and growth of piglets to weaning. Applied Animal Behaviour Science 33(2-3), 191-208

Cronin, G.M., Smith, J.A., Hodge, F.M. and Hemsworth, P.H. 1994. The behavior of primiparous sows around farrowing in response to restraint and straw bedding. Applied Animal Behaviour Science 39: 269-280.

Cronin, G.M., Dunsmore, B., Leeson, E., 1998. The effects of farrowing nest size and width on sow and piglet behaviour and piglet survival. Applied Animal Behaviour Science 60, 331-345.

Damm, B.I. and Pedersen, L.J., 2000. Eliminative behaviour in preparturient gilts previously kept in pens or stalls. Acta Agriculturae Scandinavica Section A-Animal Science 50: 316-320.

Damm, B.I., Pedersen, L.J., Marchant-Forde, J.N. and Gilbert, C.L. 2003. Does feed-back from a nest affect periparturient behaviour, heart rate and circulatory cortisol and oxytocin in gilts? Applied Animal Behaviour Science 83, 55-76.

Damm, B.I., Forkman, B., Pedersen, L.J., 2005. Lying down and rolling behaviour in sows in relation to piglet crushing. Applied Animal Behaviour Science 90, 3-20.

Damm, B.I., Moustsen, V., Jorgensen, E., Pedersen, L.J., Heiskanen, T., Forkman, B., 2006. Sow preferences for walls to lean against when lying down. Applied Animal Behaviour Science 99, 53-63.

Danholt, L., Moustsen, V.A., Nielsen, M.B.F., Kristensen, A.R., 2011. Rolling behaviour of sows in relation to piglet crushing on sloped versus level floor pens. Livestock Science 141, 59-68.

Edwards, S.A., Fraser, D., 1997. Housing systems for farrowing and lactation. The Pig Journal 39, 7789.

Edwards, S.A. 2002. Perinatal mortality in the pig: environmental or physiological solutions? Livestock Production Science 78, 3-12.

European Food Safety Authority 2007. Animal health and welfare aspects of different housing and husbandry systems for adult breeding boars, pregnant, farrowing sows and unweaned piglets [1], pp. 1-13. Scientific Opinion of the Panel on Animal Health and Welfare, EFSA.

Gäde, S., Bennewitz, J., Kirchner, K., Looft, H., Knap, P.W., Thaller, G. and Kalm,E. 2008. Genetic parameters for maternal behaviour traits in sows. Livestock Science 114 (1), 31-41 
Grandinson, K., Rydhmer, L., Strandberg, E. and Thodberg, K. 2003. Genetic analysis of on-farm tests of maternal behaviour in sows. Livestock Production Science 83(2-3), 141-151

Guy, J.H., Cain, P.J., Seddon, Y.M., Baxter, E.M., Edwards, S.A., 2012. Economic evaluation of high welfare indoor farrowing systems for pigs. Animal Welfare 21, 19-24.

Hunt, K., Petchey, A.M., 1987. A Study of the Environmental Preferences of Sows Around Farrowing. Farm Building Progress, 11-14.

Illmann, G., Neuhauserová, K., Pokorná, Z., Chaloupková, H. and Šimečková, M. 2008. Maternal responsiveness of sows towards piglet's screams during the first $24 \mathrm{~h}$ postpartum. Applied Animal Behaviour Science 112, 248-259.

Jarvis, S., Lawrence, A.B., Mclean, K.A., Deans, L.A., Chirnside, J. and Calvert, S.K. 1997. The effect of environment on behavioural activity, ACTH, beta-endorphin and cortisol in pre-farrowing gilts. Animal Science 65, 465-472

Jarvis, S., Calvert, S.K., Stevenson, J., van Leeuwen, N. and Lawrence, A.B. 2002. Pituitary-adrenal activation in pre-parturient pigs (Sus scrofa) is associated with behavioural restriction due to lack of space rather than nesting substrate. Animal Welfare 11, 371-384.

Malmkvist, J., Pedersen, L.J., Kammersgaard, B. M. T. and Jorgensen, E. 2012. Influence of thermal environment on sows around farrowing and during the lactation period. Journal of Animal Science 90, 3186-3199.

Marchant, J.N., Broom, D.M., and Corning, S., 2001. The influence of sow behaviour on piglet mortality due to crushing in an open farrowing system. Animal Science 72, 19-28.

Marchant-Forde, J.N. 2002. Piglet- and stockperson-directed sow aggression after farrowing and the relationship with a pre-farrowing, human approach test. Applied Animal Behaviour Science 75(2), 115-132

Mount, L.E., 1967. The heat loss from new-born pigs to the floor. Research in Veterinary Science 8, 175-186.

Moustsen, V.A., Lahrmann, H.P., and D'Eath, R.B., 2011. Relationship between size and age of modern hyper-prolific crossbred sows. Livestock Science 141, 272-275.

NAHMS (National Animal Health Monitoring System). 2000. Part I. Reference of swine health and management in the United States. CO, U.S.A.

Pedersen, L.J., Damm, B.I., Marchant-Forde, J.N. and Jensen, K.H. 2003. Effects of feed-back from the nest on maternal responsiveness and postural changes in primiparous sows during the first $24 \mathrm{~h}$ after farrowing onset. Applied Animal Behaviour Science 83, 109-124.

Pedersen, L.J., Malmkvist, J., Jorgensen, E., 2007. The use of a heated floor area by sows and piglets in farrowing pens. Applied Animal Behaviour Science 103, 1-11.

Phillips, P.A., Fraser, D., Pawluczuk, B., 2000. Floor temperature preference of sows at farrowing. Applied Animal Behaviour Science 67, 59-65. 
Prunier A., de Braganca M. M. and Le Dividich J. 1997. Influence of high ambient temperature on performance of reproductive sows. Livestock Production Science 52, 123-133.

516

517

518

519

520

521

522

523

524

525

526

527

528

529

530

531

532

533

534

535

536

537

538

539

540

541

542

543

544

545

Rohde, K.A., Gonyou, H.W., 1987. Strategies of Teat-Seeking Behavior in Neonatal Pigs. Applied Animal Behaviour Science 19, 57-72.

Stolba, A., Wood-Gush, D.G.M., 1984. The identification of behavioural key features and their incorporation into a housing design for pigs. Annales de Recherches Veterinaires 15, 287299.

Thodberg, K., Jensen, K.H. and Herskin, M.S. 2002. Nest building and farrowing in sows: relation to the reaction pattern during stress, farrowing environment and experience. Applied Animal Behaviour Science 77(1), 21-42

Valros, A., Rundgren, M., Spinka, M., Saloniemi, H. and Algers, B. 2003. Sow activity level, frequency of standing-to-lying posture changes and anti-crushing behaviour--within sow-repeatability and interactions with nursing behaviour and piglet performance. Applied Animal Behaviour Science 83(1), 29-40

Vasdal, G., Glærum, M., MelišováM., BØe, K.E., Broom, D.M., and Andersen, I.L., 2010. Increasing the piglets' use of the creep area--A battle against biology? Applied Animal Behaviour Science 125, 96-102.

Weary, D.M., Pajor, E.A., Thompson, B.K., Fraser, D., 1996a. Risky behaviour by piglets: A trade off between feeding and risk of mortality by maternal crushing? Animal Behaviour 51, 619-624.

Weary, D.M., Pajor, E.A., Fraser, D., Honkanen, A.M., 1996b. Sow body movements that crush piglets: a comparison between two types of farrowing accommodation. Applied Animal Behaviour Science 49, 149-158.

Wechsler, B. and Hegglin, D. 1997. Individual differences in the behaviour of sows at the nest-site and the crushing of piglets. Applied Animal Behaviour Science 51, 39-49.

Wiepkema, P.R. 1986. Remarks on the behaviour of wild boar. Applied Animal Behaviour Science 15, 179-180.

Wischner, D. Kemper, N. and Krieter, J. 2009. Nest-building behaviour in sows and consequences for pig husbandry. Livestock Science 124, 1-8.

Yun, J., Swan, K.M., Vienola, K., Farmer, C., Oliviero, C., Peltoniemi, O. and Valros, A., 2013. Nestbuilding in sows: Effects of farrowing housing on hormonal modulation of maternal characteristics. Applied Animal Behaviour Science 148, 77-84. 